\title{
Severe Brain Damage in a Moderate Preterm Infant as Complication of Post-COVID-19 Response during Pregnancy
}

\author{
Viktoria Engert $^{\mathrm{a}}$ Celine Siauw $^{\mathrm{a}}$ Annika Stock $^{\mathrm{b}}$ Monika Rehn $^{\mathrm{c}}$ \\ Achim Wöckel $^{c}$ Christoph Härtel $^{\mathrm{a}} \quad$ Johannes Wirbelauer ${ }^{\mathrm{a}}$

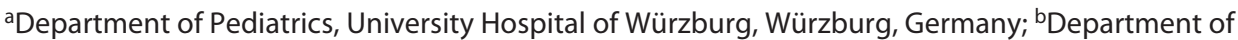 \\ Neuroradiology, University Hospital of Würzburg, Würzburg, Germany; ' Department of Obstetrics and \\ Women's Health, University Hospital of Würzburg, Würzburg, Germany
}

\section{Established Facts}

- SARS-CoV-2 infections may be transmitted in utero and in the perinatal period.

- Multisystem inflammatory syndromes can occur after SARS-CoV-2 infections, particularly in the first 2 decades of life.

\section{Novel Insights}

- SARS-CoV-2 infection during pregnancy may cause neurological damage to the fetus.

- Etiological workup of unusual neonatal presentations should include serological screening for SARSCoV-2 antibodies, in particular during COVID-19 pandemic.

\section{Keywords}

Intracranial hemorrhage · Periventricular leukomalacia ·

COVID-19. Newborn bleeding and periventricular leukomalacia as a potential consequence of post-COVID-19 hyperinflammation during pregnancy.

(c) 2021 The Author(s)

Published by S. Karger AG, Basel

\section{Abstract}

Current evidence from the COVID-19 pandemic suggests that neonatal SARS-coronavirus-2 infections usually have a mild course. Data on how maternal infection during pregnancy affects fetal development are scarce. We present the unique case of a moderate preterm infant with intracranial

karger@karger.com www.karger.com/neo

Karger $\stackrel{\text { ' }}{5}$ BOPEN ACCESS
(C) 2021 The Author(s)

Published by S. Karger AG, Basel

This is an Open Access article licensed under the Creative Commons Attribution-NonCommercial-4.0 International License (CC BY-NC) (http://www.karger.com/Services/OpenAccessLicense), applicable to the online version of the article only. Usage and distribution for commercial purposes requires written permission.

\section{Introduction}

It is well acknowledged that infections during pregnancy with specific viruses, for example, cytomegalovirus, rubella virus, and zika virus, may represent major 
causes of permanent neurological disability in children. Current experience of the COVID-19 pandemic suggests that SARS-CoV-2 infection in pregnant women is associated with a higher risk for preterm delivery but usually mild or uneventful neonatal courses. Potential neurological manifestations of SARS-CoV-2 infection in the newborn are yet unclear [1-5]. Here, we report the complication of intracranial hemorrhage and periventricular leukomalacia in a moderate preterm infant born after maternal hyperinflammatory response following SARS$\mathrm{CoV}-2$ infection during the 2 nd trimester of pregnancy.

\section{Case Report}

\section{Perinatal History}

The 25 -year-old mother presented at 33 weeks of gestation with preterm labor but no other clinical abnormalities. Apart from mild cold symptoms at 16 weeks of gestation, maternal history including immune-mediated and coagulation disorders was unremarkable. Laboratory evaluation revealed increased markers of inflammation, for example, C-reactive protein $14.5 \mathrm{mg} / \mathrm{dL}$ and a total white blood cell (WBC) count of $18.3 / \mathrm{nL}$ with normal platelet counts and coagulation studies. There was no focus for any infection. Due to pathological cardiotocography and maternal signs of inflammation, caesarean section was performed at 33 5/7 weeks. The histological examination of the placenta revealed no signs of funisitis, chorioamnionitis, or placental infarction. Microbiological evaluation of swabs (cervix and placenta) was negative for any pathogen.

\section{Neonatal Course}

The preterm infant presented with Apgar score 4/7/7 after 1, 5 , and $10 \mathrm{~min}(\mathrm{pH} 7.28$, base excess $-5.0 \mathrm{mmol} / \mathrm{L}$ ) and transitory tachypnea which was well controlled with respiratory support using continuous positive airway pressure. Ubiquitous petechial bleedings and pale hematomas were noticed on the skin but no other signs of clinical infection (shown in Fig. 1). Birth weight $(2,100 \mathrm{~g}, 43 \mathrm{rd}$ percentile), length $(45 \mathrm{~cm}, 48 \mathrm{th}$ percentile), and head circumference $(30 \mathrm{~cm}, 21 \mathrm{st}$ percentile) were appropriate for gestational age. Day 1 cerebral ultrasound demonstrated cortical hyperechogenicity and cystic periventricular lesions (shown in Fig. 2). Laboratory studies revealed increased numbers of WBC (48.6/nL, nucleated red blood cells 27/100 WBCs), slightly increased procalcitonin $(2.1 \mathrm{ng} / \mathrm{mL}, \mathrm{ref}<0.5 \mathrm{ng} / \mathrm{mL})$, but unremarkable C-reactive protein $(<0.1 \mathrm{mg} / \mathrm{dL})$. The initial hemoglobin value $(17.9 \mathrm{~g} / \mathrm{dL}$, ref. $14.3-19 \mathrm{~g} / \mathrm{dL})$ was normal and the platelet count at the lower margin of reference values $(132 / \mathrm{nL}$, ref. $150-450 / \mathrm{nL})$. Coagulation studies, however, were pathological, that is, INR 3.55 (ref. 1-2), PTT $>160 \mathrm{~s}$ (ref. 23-75 s), D-dimers $>35.2 \mathrm{mg} / \mathrm{L}$ (ref. $<0.5 \mathrm{mg} / \mathrm{L}$ ), and fibrinogen $<0.4 \mathrm{~g} / \mathrm{L}$ (ref., $2.8-4 \mathrm{~g} / \mathrm{L}$ ). After transfusion of $20 \mathrm{~mL} / \mathrm{kg}$ fresh frozen plasma, the coagulation parameters completely normalized. Evaluation of the cerebrospinal fluid (CSF) demonstrated normal protein $(121 \mathrm{mg} / \mathrm{dL})$ and glucose $\mathrm{CSF} /$ plasma values $(0.48)$ as well as WBC count $(31 / \mu \mathrm{L}$, red blood cells $1,300 / \mu \mathrm{L})$. Microbiological blood and CSF cultures were sterile. Congenital infection with rubella virus, cytomegalovirus, her-

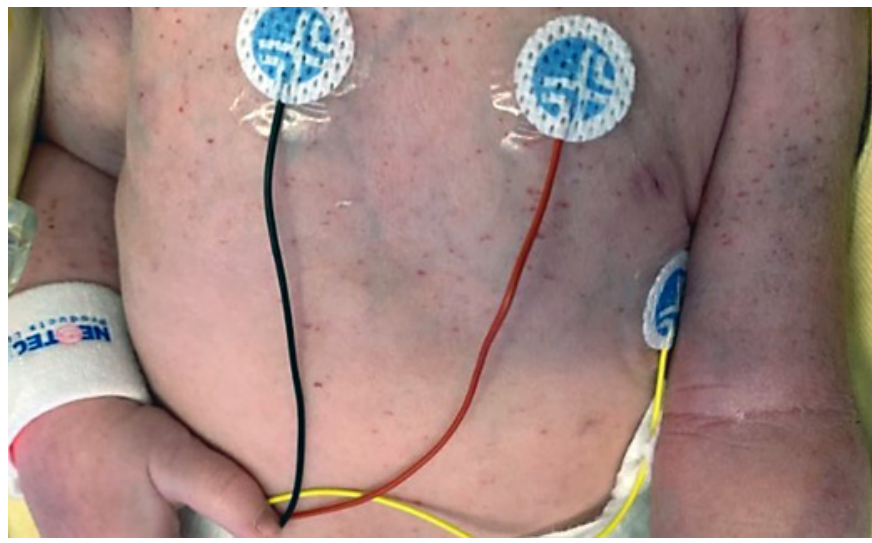

Fig. 1. Initial presentation of the skin with ubiquitous petechial bleedings at the trunk and extremities indicating coagulopathy and/or vasculitis (endotheliitis).

pes-simplex virus, and toxoplasmosis was ruled out. MRI performed on day 14 of life confirmed bilateral intracranial bleedings in and outside the brain parenchyma with frontal accentuation (shown in Fig. 3).

\section{Maternal COVID-19 Infection}

Maternal serology testing for SARS-CoV-2 (ELISA) revealed IgG antibodies against S1-protein (1.2 ratio; pos >1.0; Euroimmun, Germany) and against N-protein (anti-N-protein IgG/IgM/ IgA index 15.2, ref. positive $>1.0$, Roche, Germany). Anti-N-protein IgG (34 U/mL, ref. positive $>24$; anti-N-protein IgG/IgM/IgA index 4.42 , ref. positive $>1.0$ ) was also prevalent in the newborn serum, while specific anti-N-protein IgM and anti-S1/S2 IgM and IgG were negative. PCR test of SARS-CoV-2 after birth was negative in the mother (swab) and infant (swab and CSF). The infant recovered well and was discharged at 36 days of life without major clinical findings for further close follow-up.

\section{Discussion}

Our case report generates the hypothesis that a postCOVID systemic inflammatory response during pregnancy affected the fetal circulation followed by a coagulopathy and preterm labor. One proposed underlying mechanism might be the placental overexpression of angiotensin-converting enzyme 2 - the SARS-CoV-2 receptor - which can critically modulate hemodynamics within the uteroplacental unit [6]. Second, the proinflammatory cytokine storm invoked by SARS-CoV-2 may induce even more severe inflammation with deleterious consequences on the fetal brain during a critical time frame (e.g., development of periventricular leukomalacia). Further mechanistic links exist between hyperinflammation, endothelial activation, and dysregulated complement 
Fig. 2. Transfontanellar ultrasound of the brain on day 1 of life. Coronal (a) and parasagittal (b) indicate hyperechogenic cortical areas (hemorrhage, white arrows) and cystic periventricular lesions (black arrows).
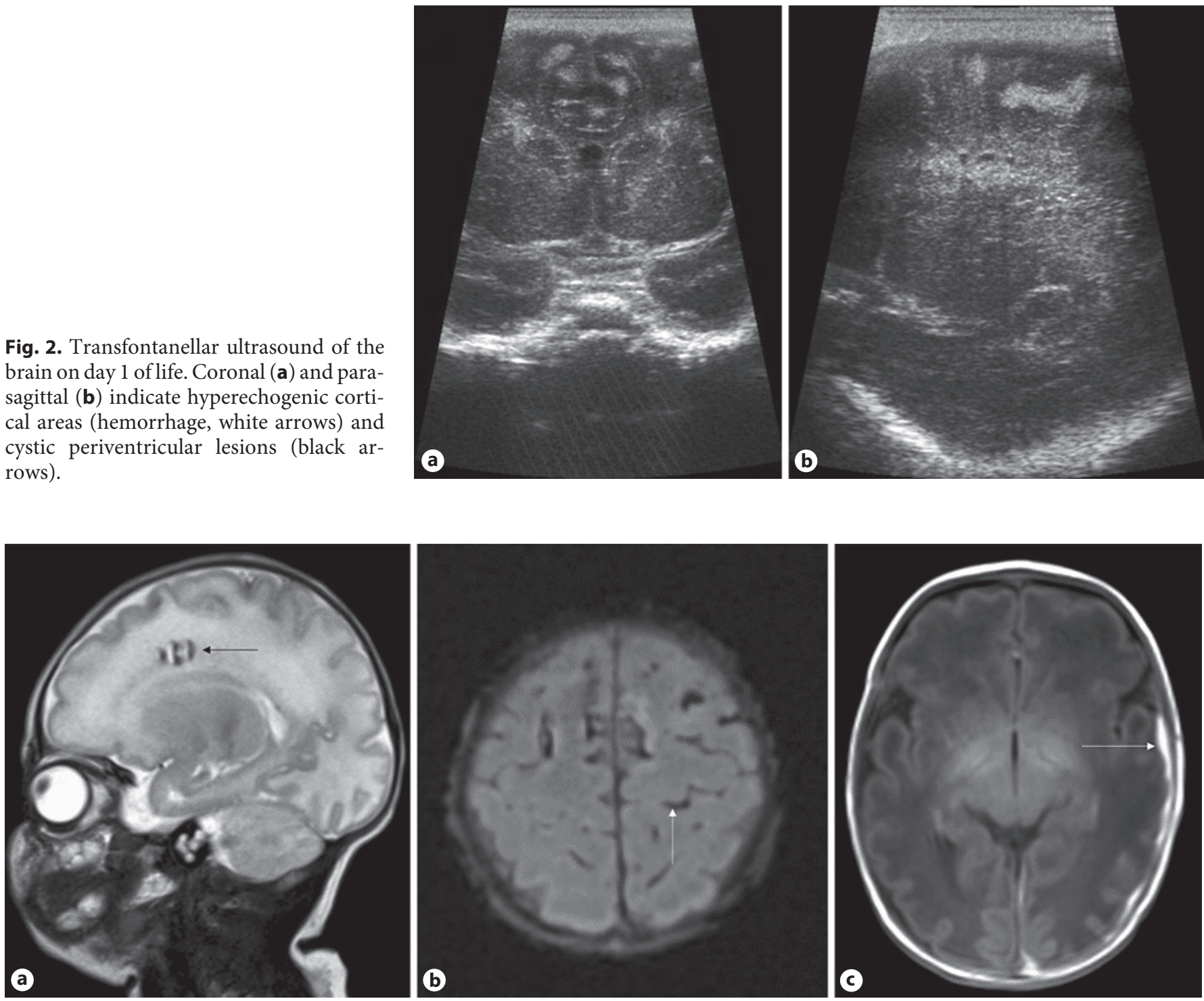

Fig. 3. Sagittal T2-weighted image shows intracerebral hemorrhage with sedimentation phenomenon (arrow) (a); blood degradation products were also found in the subarachnoid spaces (arrow) on susceptibility-weighted images (b) and subdural on the left side, exemplary on T1-weighted images (c).

function which are known pathways to mediate microvascular injury, vasculitis, and coagulopathy [7-9].

Systemic inflammatory responses and coagulation disturbances are known complications of acute SARS-CoV-2 infection in intensive care patients [10,11]. Hyperinflammatory responses also occur with temporal delay of several months after SARS-CoV-2 infection, for example, multisystem inflammatory syndrome in children. With a predominance in the first decades of life, post-COVID hyperinflammation is rather related to antibody-dependent enhancement of acquired immune responses to virus than direct virus replication. In the case of a 16-year-old boy, vascular inflammation was reported including stenosis of cerebral vessels leading to stroke [8]. In the specific context of immunotolerance during pregnancy, neonatal consequences of post-COVID hyperinflammation have not been described yet. In our unique case, diagnostic signs of inflammation and coagulopathy were intracranial and petechial bleeding (without abnormal platelet count) as well as highly elevated D-dimers and WBC count.

Two other case reports describe neurological symptoms in newborns in relation to a SARS-CoV-2 infection 
due to perinatal transmission. The newborns presented with encephalitic symptoms such as lethargy, irritability, axial hypertonia, and high-pitched crying but unremarkable CSF results. Cerebral imaging was normal in 1 affected infant, while white matter injury was diagnosed in the other case being suggestive for cerebrovascular inflammation $[12,13]$.

To our knowledge, we present the first report of severe brain damage as a potential consequence of SARS-CoV2-mediated hyperinflammation during pregnancy. We propose that the current pandemic situation requires serological screening of mother-infant dyads for SARSCoV-2 antibodies when unusual clinical appearances of vasculitis, inflammation, or coagulopathy are obvious. Furthermore, all infants of mothers with known SARS$\mathrm{CoV}-2$ infection during pregnancy should be monitored for adverse neurological findings.

\section{Acknowledgment}

Virological diagnostics was performed by Dr. Benedict Weißbrich, Institute of Virology, University of Würzburg.

\section{Statement of Ethics}

The parents have given their written informed consent to publish the case including publication of images.

\section{Conflict of Interest Statement}

The authors have no conflicts of interest to declare.

\section{Funding Sources}

There is no particular funding to the manuscript.

\section{Author Contributions}

V.E., J.W., and C.H. drafted the first version of the manuscript. C.S., M.R., A.W., V.E., J.W., and C.H. were involved in the treatment of mother and infant. A.S. performed MR imaging and interpreted imaging finding. All authors have read and critically revised the final version of the manuscript.

\section{References}

1 Stafstrom CE, Jantzie LL. COVID-19: neurological considerations in neonates and children. Children. 2020;7(9):133.

2 Dumitriu D, Emeruwa UN, Hanft E, Liao GV, Ludwig E, Walzer L, et al. Outcomes of neonates born to mothers with severe acute respiratory syndrome coronavirus 2 infection at a large medical center in New York City. JAMA Pediatr. 2021;175(2):157-67.

3 Nakra NA, Blumberg DA, Herrera-Guerra A, Lakshminrusimha S. Multi-system inflammatory syndrome in children (MIS-C) Following SARS-CoV-2 infection: review of clinical presentation, hypothetical pathogenesis, and proposed management. Children. 2020; 7(7):69.

4 Di Nardo M, van Leeuwen G, Loreti A, Barbieri MA, Guner Y, Locatelli F, et al. A literature review of 2019 novel coronavirus (SARSCoV2) infection in neonates and children. Pediatr Res. 2020.
5 Raschetti R, Vivanti AJ, Vauloup-Fellous C, Loi B, Benachi A, De Luca D. Synthesis and systematic review of reported neonatal SARSCoV-2 infections. Nat Commun. 2020;11(1): 5164.

6 Levy A, Yagil Y, Bursztyn M, Barkalifa R, Scharf S, Yagil C. ACE2 expression and activity are enhanced during pregnancy. Am J Physiol Regul Integr Comp Physiol. 2008; 295(6):R1953-61.

7 Song WC, Fitzgerald GA. COVID-19, microangiopathy, hemostatic activation, and complement. J Clin Invest. 2020;130(8):3950-3.

8 Varga Z. Endothelial cell infection and endotheliitis in COVID-19. Lancet. 2020; 395(10234):1417-8.

9 McGonagle D, Bridgewood C, Ramanan AV, Meaney JFM, Watad A. COVID-19 vasculitis and novel vasculitis mimics. Lancet Rheumatol. 2021;3(3):e224-33.
10 Tan CW, Tan JY, Wong WH, Cheong MA, $\mathrm{Ng}$ IM, Conceicao EP, et al. Clinical and laboratory features of hypercoagulability in COVID-19 and other respiratory viral infections amongst predominantly younger adults with few comorbidities. Sci Rep. 2021; 11(1):1793.

11 Oualha M, Bendavid M, Berteloot L, Corsia A, Lesage F, Vedrenne M, et al. Severe and fatal forms of COVID-19 in children. Arch Pediatr. 2020;27(5):235-8.

12 Lorenz N, Treptow A, Schmidt S, Hofmann R, Raumer-Engler M, Heubner G, et al. Neonatal early-onset infection with SARS-CoV-2 in a newborn presenting with encephalitic symptoms. Pediatr Infect Dis J. 2020;39(8):e212.

13 Vivanti AJ, Vauloup-Fellous C, Prevot S, Zupan V, Suffee C, Do Cao J, et al. Transplacental transmission of SARS-CoV-2 infection. Nat Commun. 2020;11(1):3572. 